Revista Oficial del Poder Judicial

ÓRGANO DE INVESTIGACIÓN DE LA CORTE SUPREMA DE JUSTICIA DE LA REPÚBLICA DEL PERÚ

Vol. 11, n. ${ }^{\circ} 13$, enero-junio, 2020, 389-403

ISSN versión impresa: 1997-6682

ISSN versión electrónica: 2663-9130

DOI: https://doi.org/10.35292/ropj.u11i13.50

\title{
Las experiencias maximizadas en el proceso. Reglas y principios de la epistemología probatoria
}

The Legal Maxims in the Legal Process. Rules and principles of the epistemology of the Proof 0

Miguel Angel ARZAPAlo CAlLupe

Pontificia Universidad Católica del Perú

(Lima, Perú)

Contacto: m.arzapalo@pucp.edu.pe

https://orcid.org/0000-0002-5615-1890

\section{RESUMEN}

Las máximas de la experiencia deben ser utilizadas teniendo en cuenta la mayor responsabilidad y su aplicabilidad, pues no pueden confundirse con conceptos que no tengan carácter universal o particular, además de no poder aplicarse ninguna moral particular, o pública, sino las experiencias concurrentes y cotidianas que le otorgan fiabilidad a estas. Por ello, la inducción de las máximas de la experiencia debe hacerse con sumo cuidado, tomando en cuenta los esquemas argumentacionales propuestos, y se debe establecer 
que la costumbre no incumbe una máxima de experiencia sino una suerte de patrón social que puede o no ser aceptado.

Palabras clave: experiencia de la máxima de la experiencia, carácter circundante, estructuras lógicas, inducción, costumbre.

\section{ABSTRACT}

The Legal Maxims will be used responsibly. This will not be confused with some universal or particular conceptions. This will be understood at the core of reiterative experience. Consequently, the evidence of legal maxims will consider the argumentative framework and the place of custom. Custom is not included in the legal maxims; it is an accepted social feature or not.

Key words: legal maxims, proof, custom.

Recibido: 03/03/2020 Aceptado: 04/06/2020

\section{DATOS DEL RECURSO DE NULIDAD N. ${ }^{\circ}$ 2792-2014}

Hace no mucho tiempo, y los recuerdos llegan, hace no tanto y los recuerdos pasan por la mente y detrás de nuestros ojos. Me refiero, claro está, a los recuerdos de antaño, de los noventa, en los que, conjuntamente con mis amigos, pedíamos el favor de prestarnos la pichina del balón de básquet o fútbol, para inflarlo, o solicitábamos prestada la canchita de fulbito para jugar, recurriendo a un amigo mayor para que nos avale y por el cual entregábamos en garantía su Libreta Electoral -ahora Documento Nacional de Identidad (en adelante DNI)-.

También recuerdo que aquella cédula de identidad, ya en la mayoría de edad, se dejaba como garantía cuando te faltaban unos cuantos soles o te fiabas del bodeguero de la esquina, hecho que viabilizaba el pago futuro de la obligación creditoria generada por la falta de recursos económicos: «iNo te preocupes, te dejo mi DNI 
y te pago mañana!, ¿vas a desconfiar de mí?», se decía. Eso sucedía y sucede hasta hoy en día muy frecuentemente, en estratos sociales bajos, y es ahí donde encontramos una experiencia recurrente e inmanente del pasar de los años.

En ese escenario surge la sentencia suprema penal, contenida en el Recurso de Nulidad n. ${ }^{\circ}$ 2792-2014-Huánuco, expedido por la Sala Penal Permanente de la Corte Suprema de Justicia de la República, que declaró no haber nulidad sobre la condena impuesta a Santillán Sánchez por el delito contra la salud pública-tráfico ilícito de drogas, en la modalidad de promoción o favorecimiento al tráfico ilícito de drogas en perjuicio del Estado, conforme a los hechos sostenidos en ella. Su decisión se fundaba en un hecho en particular, que para el presente trabajo significará el análisis de dicho marco de argumentación probatoria, en cuanto a las máximas de la experiencia.

En efecto, el hecho que describe la Sala Suprema es el siguiente: señala que Santillán Sánchez había prestado su DNI a un fémina de apelativo la Gringa, a fin de enviar una encomienda - un costal con frutas - desde la ciudad de Aucayacu hacia la ciudad de Lima, hecho que se efectuó el día 8 de septiembre de 2008, pues ante la negativa inicial del personal de la agencia de transportes de la empresa Trans Inter, de permitírsele enviar una encomienda sin tener ningún documento de identidad, la Gringa procedió a acercarse nuevamente a la empresa de transportes, portando esta vez el DNI y copia del documento de Santillán Sánchez, quien estaba en las afueras del local con un bebé de cinco meses de edad en brazos, dentro del motocar que previamente se había utilizado para el traslado de dicho objeto criminal.

En su defensa, la sentenciada señaló que no era responsable del hecho imputado, o sea, promover o favorecer el tráfico de estupefacientes, dado que el día de los hechos, ella solo hizo un favor 
por agradecimiento a una persona que la ayudó antiguamente, al ser abordada por su vecina la Gringa, que vendía fruta en el mercado de Aucayacu. Dicha persona le suplicó que le ayude a enviar una encomienda hacia la ciudad de Lima; por lo cual la sentenciada aceptó y le prestó su DNI, por gratitud, al haberla supuestamente salvado y tratado de un problema de posparto, pues la Gringa fungía de curandera de dicho lugar.

En ese escenario los jueces supremos razonaron que tales abducciones argumentacionales fueron meras cuestiones defensivas sin mayor credibilidad, por lo que frente al hecho de prestar el DNI a un desconocido, crearon una regla maximalista - o una regla de máxima de la experiencia - en la cual señalaron que no es normal que una persona preste su DNI a un extraño para que realice un trámite de esa naturaleza: enviar una encomienda. Sostuvieron, como resultado de la regla creada, que ella sabía del contenido ilícito de la encomienda y, en consecuencia, la sentencia y la condena impuestas se encontraban debidamente motivadas.

\section{LA EXPERIENCIA CIRCUNDANTE DENTRO DEL CONCEPTO DE LAS MÁXIMAS DE LA EXPERIENCIA}

Ahora bien, sobre aquella decisión tomada, cabe preguntarse: ¿nuestros jueces supremos entendieron que es una máxima de la experiencia, o no? Si decimos que sí, entonces, seguramente nos enfrentaremos a una vulneración del derecho a la motivación, pues la decisión así expresada crea un estado de indefensión, dado que la abducción fáctica resulta ser una sospecha sin mayor sostenimiento respecto al principio de universalidad general y sí lo es sobre una universalidad particular y puntual que no lo devela totalmente y por lo cual resulta arbitraria. Si decimos que no, entonces debemos recrear todo el panorama probatorio para de ese modo establecer la luz de una máxima de la experiencia. 
Así, resulta imperativo determinar, en principio, que la experiencia es una forma de conocimiento que se origina por la recepción inmediata de una impresión percibida por los sentidos, lo cual supone que lo experimentado no sea un fenómeno transitorio, sino que amplía y enriquece el pensamiento de manera estable, permitiendo elaborar enunciados que impliquen generalizaciones para fijar ciertas reglas con pretensión de universalidad, expresadas con la fórmula «Siempre o casi siempre que se da $A$, entonces sucede B» (Corte Suprema de Justicia de la República de Colombia, 2016, p. 1530).

En efecto, estas generalizaciones se construyen a partir del cumplimiento estable e histórico de ciertas conductas similares, que sirven como enlace lógico o parte del razonamiento que vincula esos datos indicadores (conocidos) que dirigen a hechos desconocidos. Esas reglas se refieren a lo dado, a los datos percibidos; pero ese dato inicial, esa base empírica puede y debe ser sometida a contraste (esto es lo que le otorga universalidad), porque si no es contrastable, solo surge una situación incierta.

Para ejemplificar mejor este panorama, veamos el siguiente hecho, ejemplo de un dato indicador, sucede en la ciudad de Madrid, España, donde muchos chicos de entre 16 y 17 años toman prestadas las cédulas de identidad de sus familiares mayores para ir a fiestas en discotecas, a fin de poder entrar y comprar licor estando una vez dentro. Esto es usual, tal como se puede comprobar de las redadas que efectúa la autoridad policial y las que aparecen publicadas en el diario El País (Martín, 2010).

Otro ejemplo de ello lo tenemos en que, actualmente, muchos jóvenes filtran su cédula de identidad en las redes sociales, para que la gente vea que es su cumpleaños, sin pensar en las consecuencias que ello origina, pues dicha información puede ser filtrada en la web, para registrarse en casinos o casas de apuesta, 
o abrir cuentas bancarias online, o solicitar préstamos o créditos en diferentes servicios, o realizar compras o ventas fraudulentas en distintos portales web, etc. (Oficina de Seguridad del Internauta, 2014).

\section{EL CARÁCTER UNIVERSAL Y PARTICULAR DE LAS MÁXIMAS DE LA EXPERIENCIA}

Como se podrá apreciar, en un mundo tan globalizado como el de ahora, en la regla creada como máxima de la experiencia por la Corte Suprema difícilmente se puede verificar algún carácter de universalidad general para todos. Más bien se puede observar que la Corte actuó y regló, con un carácter de universalidad particular circunscrito en un determinado espacio y lugar, atribuyendo una fuerte sospecha por intuición - que Santillán Sánchez era parte de la organización de tráfico ilícito de drogas-, atribuyendo también como dato oculto que cualquier poblador de la ciudad de Aucayacu — ciudad del interior de la selva nororiente del Perú - tenía que saber que no se debía prestar el DNI a un extraño, dado que en dicha ciudad existe mucho tráfico ilícito de drogas ${ }^{1}$.

Esta estructura lógica de inferencia en el procedimiento probatorio aplica una probabilidad que no conduce necesariamente a un resultado como el indicado por la Corte Suprema, ya que al verificar la prueba indiciaria —el préstamo del DNI-, la inferencia utilizada veladamente es una simple máxima de la experiencia oculta (hay mucho tráfico ilícito de drogas en Aucayacu) que condujo a un resultado solo posible pero no necesario, pues la Sala Penal Permanente no ponderó que debía determinar si la regla maximalista podía tener un contenido más concreto en su resultado de aplicación.

1 Conforme también se puede ver del Plan Nacional de Prevención y Control de Drogas, Decreto Supremo n. ${ }^{\circ}$ 82-94-P.M. 
Por ello, debemos recordar que:

[conforme a] la epistemología garantista, el derecho penal de los ordenamientos desarrollados es un producto predominantemente moderno. Los principios sobre los que se funda su modelo garantista clásico - la estricta legalidad, la materialidad, y lesividad de los delitos, la responsabilidad personal, el juicio contradictorio entre partes y la presunción de inocencia- en gran parte son, como es sabido, el fruto de la tradición jurídica ilustrada y liberal.

Los filones que se entreveran en esta tradición, madurada en el siglo XVIII, son muchos y distintos: las doctrinas de los derechos naturales, las teorías contractualistas, la filosofía racionalista y empirista, las doctrinas políticas de la separación de poderes y de la supremacía de la ley, el positivismo jurídico y las concepciones utilitaristas del derecho y de la pena (Ferrajoli, 2006, p. 33).

En ese sentido, una máxima de la experiencia está constituida por las generalizaciones empíricas realizadas a partir de la observación de la realidad, obtenidas por medio de un argumento por inducción (una inducción ampliativa o generalizadora); es decir, estas constituyen pautas que provienen de la experiencia general, de contexto cultural y científico, de sentido común y de la sociedad (Coloma y Agüero, 2014, p. 400). Por esa razón las presunciones pueden verse como máximas de experiencias institucionalizadas y autoritativas; sin embargo, estas deben estar bien apoyadas por una inducción sólida que las respalde y las defienda, y deben estar apoyadas por una verdad incontrastable y de fuerte consenso social (Stein, 1988, pp. 31-34).

La regulación actual de las máximas de la experiencia la encontramos en cada código procesal, sea este civil, penal o constitucional, etc., cuya fuente constitucional es lo dispuesto por el artículo 139, inciso 3, de la Constitución nacional, es decir, toda persona tiene derecho a la aplicación de los principios de razón suficiente, no contradicción y tercio excluido, contenidos en una 
máxima de la experiencia, subespecie del derecho a la valoración de la prueba, subespecie del derecho a la prueba, subespecie del derecho fundamental a probar, subespecie del derecho al debido proceso legal.

\section{ESTRUCTURAS LÓGICAS DE LA MÁXIMA DE LA EXPERIENCIA}

Podemos decir que, para crear una regla maximizada en la experiencia, se tiene que establecer en principio el sentido común sobre el hecho, apoyado sobre las diversas experiencias generales, ocurridas en el mundo circundante, tomando en cuenta el contexto cultural del hecho, y el contexto científico del que se trate para poder generalizarlo. De otro modo, solamente se hablaría de la moral social, o la moral legalizada, o una particularidad de moral que detenta el juez, lo cual no puede ser erigido como una regla de máxima de la experiencia. Por ello debemos tomar en cuenta el esquema argumentacional n. ${ }^{\circ} 1$.

\section{Esquema argumentacional $n .{ }^{0} 1$}

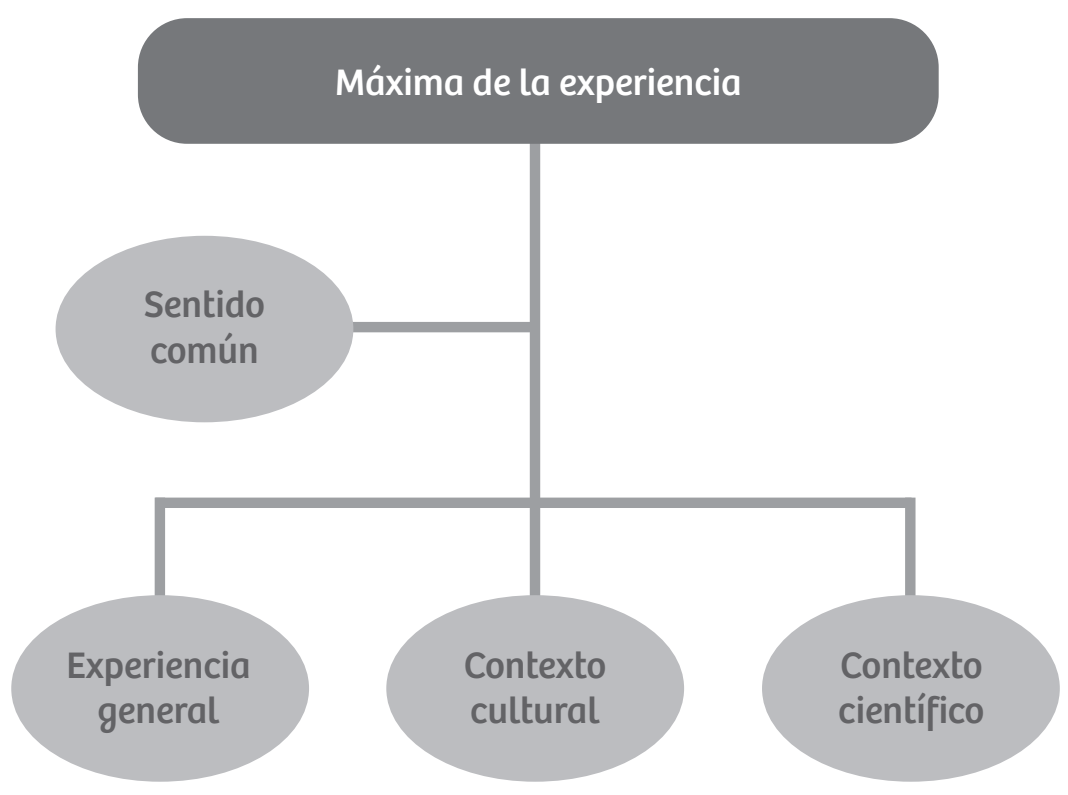


En ese sentido, conviene recordar que la doctrina mayormente autorizada (Higa, s. f.) señala que, para analizar una regla generalizadora y para aplicarla a la máxima de la experiencia, se tiene que también tomar en cuenta los cuantificadores para poder verificar qué tan sólida es la inferencia que se acaba de producir - esto es por regla de contraste-, para determinar los diversos componentes de la inferencia creada como regla generalizadora que dan sustento a esa inferencia. Una regla de máxima de la experiencia no solamente se circunscribe a establecer generalidades del mundo real, sino también particularidades de ella, dado que la generalidad, por encima de la particularidad, si no se puntualiza, no atribuye ninguna máxima de experiencia, sino que debe ser condicionada a la determinación de ciertos componentes probatorios, como se explica en el esquema argumentacional n. ${ }^{\circ} 2$.

\section{Esquema argumentacional $n .^{\circ} 2$}

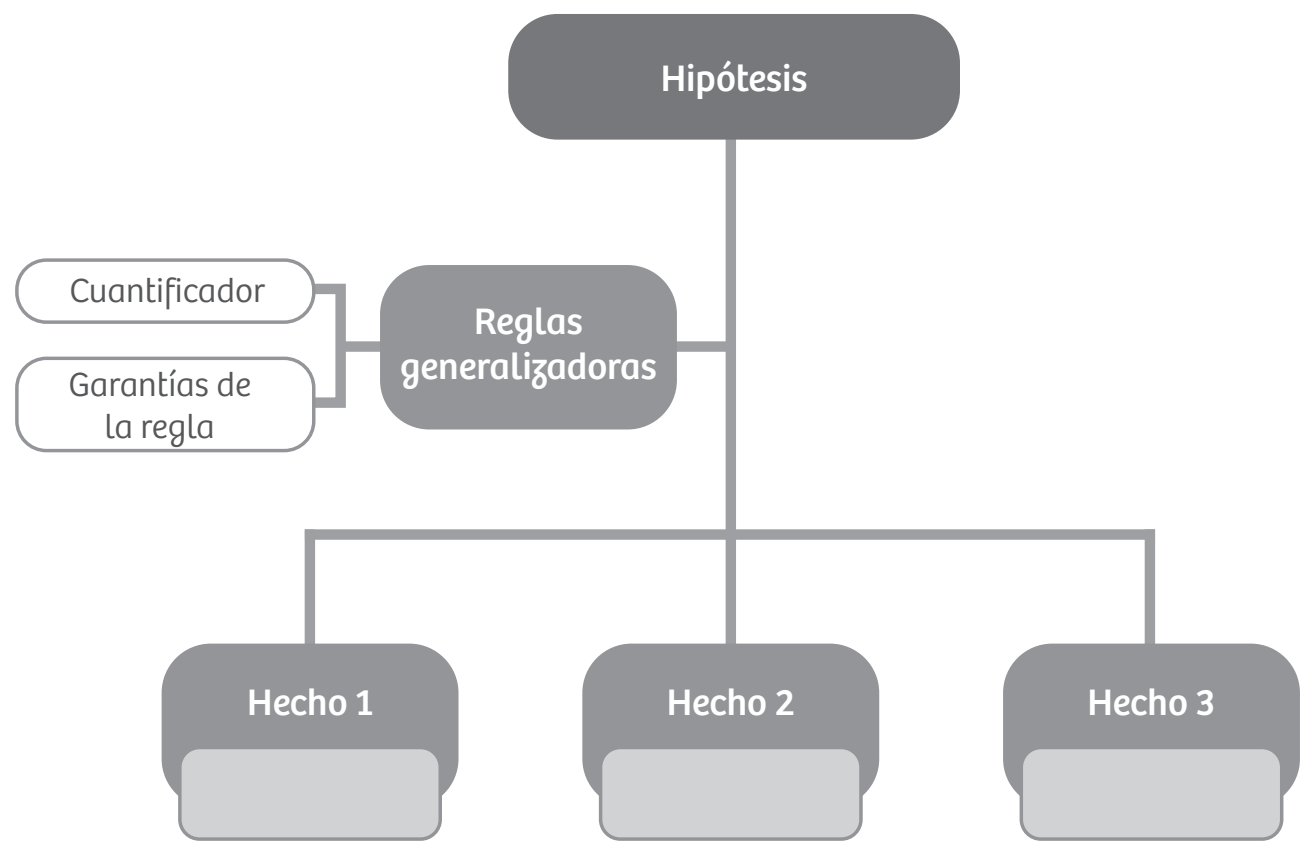


Se debe ponderar que, "para analizar qué tan sólida es la inferencia de los hechos a la hipótesis es necesario evaluar los diversos componentes de la regla generalizadora que le darán sustento a esa inferencia» (Higa, s. f., p. 14); por lo cual, el juez debe hacerse el siguiente análisis inductivo:

- Identificar cuál es la regla generalizadora que utilizan para sustentar la inferencia de los hechos a la hipótesis;

- Identificar cuál es el sustento de esas reglas: la ciencia; máximas de experiencia de la comunidad; o privadas del juez;

- Analizar y evaluar qué tan corroborada se encuentra la regla generalizadora para explicarnos el funcionamiento de la realidad o el comportamiento de las personas;

- Analizar qué grado de generalidad tienen esas reglas sobre la realidad y, en específico, en el contexto en que se pretenden aplicar;

- Determinar cómo se aplica la regla a los hechos concretos del caso; $y$,

- Evaluar cómo se enfrentarán situaciones de incertidumbre en caso existan varias hipótesis explicativas de los hechos del caso (Higa, s. f., p. 14).

Por otro lado, para determinar en qué momento estamos frente a la inducción con vocación de entramar una máxima de experiencia, primeramente debemos analizar:

cuando generalizamos a partir de un número de casos de los que algo es verdad, e inferimos que la misma cosa es verdad de una clase entera. $\mathrm{O}$, cuando hallamos que cierta cosa es verdadera de cierta proporción de casos, e inferimos que es verdadera de la misma proporción de la clase entera (Peirce, 1968, pp. 44-49). 


\section{LA INDUCCIÓN EN LA MÁXIMA DE LA EXPERIENCIA}

Sin embargo, desde el punto de vista de la aceptabilidad de la conclusión de una prueba deductiva llevada a una máxima de la experiencia, el punto más débil no lo constituyen las reglas universales sobre las que se apoyan las máximas de la experiencia, sino la posible fragilidad epistemológica de las aseveraciones (enunciados probatorios) sobre hechos singulares (Gascón, 2010, p. 91). Por este motivo, podemos afirmar que sobre las pruebas deductivas fundadas en reglas cuya universalidad ni siquiera puede cuestionarse, como la prueba - por signos- (por ejemplo, la regla de la máxima de la experiencia del parto es el signo de embarazo previo) o la coartada (fundada en la regla como máxima de la experiencia: nadie puede estar en dos sitios a la vez), conviene mantener una actitud cautelosa, pues la premisa menor de la inferencia deductiva puede ser falsa, dado que puede ser falso que el parto se produjera, o que alguien estuviera en determinado lugar a una hora precisa. En relación con la prueba documental, la consideración precedente resulta igualmente clara, pues, por ejemplo, el acta de registro donde se plasma la fecha de nacimiento acredita (por obra de una norma jurídica que tiene la estructura de una regla de máxima de experiencia universal) la edad de la persona registrada; empero, tal acta puede haber sido manipulada, con lo cual la máxima que se pretende erigir como modelador del hecho exógeno, termina corrompiendo la fuente probatoria y el mismo proceso en sí.

Asimismo, no debe olvidarse que la ciencia, en cuanto a su modelo de contexto científico, debe también verificar las «ciencias duras»:

como la ingeniería, la biología, la química o las matemáticas, que estarían comprendidas dentro del concepto natural de «ciencia»y, por tanto, el juez al valorarlas tiende a renunciar a su conocimiento privado y opta por recurrir a la opinión de expertos en el área. Por otro lado, existirían las ciencias «humanas o blandas» como la psicología, la historia, entre otras ciencias sociales, las cuales 
se han mirado tradicionalmente como parte del acervo cultural del juez o de su conocimiento común, y, por tanto, tenderían a ser infravaloradas por los jueces respecto de las ciencias duras (Oyarzún, 2016, p. 21).

Volviendo al caso que nos ocupa, se tiene que la Sala Suprema creyó conveniente aplicar una máxima plagada de percepciones ocultas, de la cual no pudo determinar más de lo que ya se había señalado. Por eso actuó y regló con un carácter de universalidad particular circunscrito en un determinado espacio y lugar, atribuyendo una fuerte sospecha por intuición - que Santillán Sánchez era parte de la organización de tráfico de drogas - y atribuyendo como dato oculto que cualquier poblador de la ciudad de Aucayacu debía saber que no se debe prestar el DNI a un extraño, pues en dicha ciudad existe mucho tráfico ilícito de drogas. Esto no puede ser considerado una máxima creada válidamente, ya que advierte una suerte de moral privada introducida como máxima.

\section{LA COSTUMBRE NO ES UNA MÁXIMA DE LA EXPERIENCIA}

Este hecho incluso confronta con la costumbre, que es fuente legal de derecho, específicamente, de derecho no inscrito, el cual otorga de modo expreso a «los usos» la calificación de fuente, puesto que la costumbre es una práctica social (vale decir, un comportamiento habitual socialmente compartido) constante, que se da repetidamente por largo tiempo, acompañada de la creencia de que dicha praxis es conforme a una norma vinculante (Guastini, 2016, pp. 237-ss.).

¿Y por qué digo que confronta? Pues porque simple y sencillamente la sentencia supra no nos indica de dónde extrae aquella premisa maximalista - es anormal prestarle el DNI a un extraño- dado que ella nunca dijo que era un extraño, sino su vecina que vendía frutas en el mercado y fungía de curandera del lugar; y también señaló que le hacía ese favor por gratitud por un hecho anterior que las vinculaba. 
Entonces queda desechada dicha máxima y, por ende, sobre el hecho se debía aplicar el aforismo consuetudo loci est observanda - «ha de observarse la costumbre del lugar». Siempre y cuando sea cierta y razonable y no se trate de un malus usus (Ortega et al., 2006, p. 126)-, pues lo que se encontraba verificándose en los hechos son costumbres de la ciudad del interior del país y en específico de la ciudad de Aucayacu, que tiene una connotación particular de la vida en convivencia y, por esto mismo, de sus usos y costumbres.

Así, entonces, recreando los hechos del caso, tenemos que: (i) el día 8 de septiembre de 2008, Santillán Sánchez había prestado su DNI a un fémina de apelativo la Gringa, a fin de enviar una encomienda - un costal con frutas - desde la ciudad de Aucayacu hacia la ciudad de Lima, pues ante la negativa inicial del personal de la agencia de transportes de la empresa Trans Inter, de permitírsele enviar una encomienda sin tener ningún documento de identidad, (ii) la Gringa procedió a acercarse nuevamente a la empresa de transportes, portando esta vez el DNI y copia del documento de Santillán Sánchez, quien estaba en las afueras del local con un bebé de cinco meses de edad en brazos, dentro del motocar que previamente se había utilizado para el traslado de dicho objeto criminal; (iii) la procesada Santillán Sánchez al prestar el DNI para mandar la encomienda, efectuó el favor en agradecimiento a una persona que la ayudó antiguamente, al ser abordada por su vecina la Gringa, que vendía fruta en el mercado de Aucayacu. Dicha persona le suplicó que le ayude a enviar una encomienda hacia la ciudad de Lima, la sentenciada aceptó y le prestó su DNI, por gratitud, ya que la salvó y trató de un problema de posparto; la Gringa fungía de curandera en el lugar, esto debe ser visto como una costumbre arraigada en dicha ciudad. Empero, debe merecer una responsabilidad restringida, pues ella debió ponderar que lo que en verdad estaba sucediendo era un típico acto de envío de encomienda ilícita. Al prestar el apoyo necesario para tal acto, la 
procesada se convirtió en cómplice primaria, ya que su ayuda y consentimiento, aunque sea por error o ignorancia, determinaron el decurso de su responsabilidad criminal. Ello, por los motivos antes expuestos, debe merecer una pena por debajo del mínimo legal, al ser una responsabilidad atenuada.

\section{COMENTARIOS FINALES}

Como se podrá apreciar, las máximas de la experiencia deben ser utilizadas teniendo la mayor responsabilidad y su aplicabilidad, pues no puede confundirse con conceptos que no tengan carácter universal o particular, además de no poder aplicarse ninguna moral particular, o pública, sino las experiencias concurrentes y cotidianas que le otorgan fiabilidad a ellas. Por este motivo, la inducción de las máximas de la experiencia debe hacerse con sumo cuidado, tomando en cuenta los esquemas argumentacionales propuestos, se debe establecer que la costumbre no incumbe una máxima de experiencia sino una suerte de patrón social que puede o no ser aceptado.

\section{REFERENCIAS}

Coloma, R. y Agüero, C. (2014). Fragmentos de un imaginario judicial de la sana crítica. Revista Ius et Praxis, 20(2), 375-414.

Corte Suprema de Justicia de la República de Colombia (2016). Sentencia Casatoria Penal SP7326-2016. Jurisprudencia y Doctrina, (536), 1530.

Ferrajoli, L. (2006). Derecho y razón: teoría del garantismo penal (8. ${ }^{\text {a }}$ ed.). Madrid: Trotta.

Gascón, M. (2010). Los hechos en el derecho: bases argumentales de la prueba (3. ${ }^{\text {e ed. }) . ~ M a d r i d: ~ M a r c i a l ~ P o n s . ~}$ 
Guastini, R. (2016). Las fuentes del derecho. Fundamentos teóricos. Lima: Raguel Ediciones.

Higa, C. (s. f.). Los esquemas argumentativos como herramienta que le facilita al juez el análisis y evaluación de los argumentos de las partes. Recuperado de http://iusfilosofiamundolatino.ua.es/ download/Los\%20esquemas\%20argumentativos\%20como $\% 20$ herramienta $\% 20$ que $\% 201$ e $\% 20$ facilita $\% 201$ a $\% 201$ ab or $\%$ 20de\%20motivaci\%C3\%B3n\%20al\%20Juez.pdf

Martín, M. (21 de febrero de 2010). Déjame tu carné para ir a la «disco». El País. Recuperado de https://elpais.com/diario/ 2010/02/21/madrid/1266755054_850215.html

Oficina de Seguridad del Internauta (17 de enero de 2014). ¿Publicar tu DNI en internet? No es una buena idea. Recuperado de https://www.osi.es/es/actualidad/blog/2014/01/17/publicar-tudni-en-internet-no-es-una-buena-idea

Ortega, J., Rodríguez, B. y Zambrana, N. (2006). Principios del derecho global. 1000 reglas y aforismos jurídicos comentados (2. ${ }^{\mathrm{a}}$ ed.). Navarra: Thomson Aranzadi.

Oyarzún, F. (2016). Aplicación de las máximas de la experiencia en un modelo de valoración racional de la prueba (Tesis de licenciatura). Universidad de Chile.

Peirce, C. (1968). Escritos lógicos. Madrid: Alianza Editorial.

Stein, F. (1988). El conocimiento privado del juez (2. ${ }^{a}$ ed.). Bogotá: Temis. 